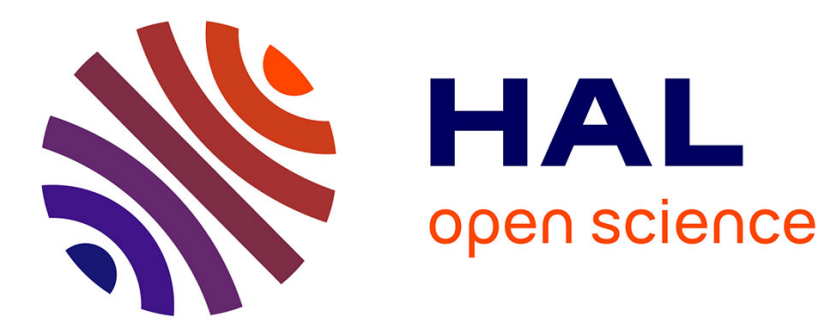

\title{
Amorphous Fe Clusters Imbedded in fcc La for Melt-Quenched La-Fe Alloys
}

M. Matsuura, M. Sakurai, K. Suzuki, H. Adachi, H. Ino

\section{To cite this version:}

M. Matsuura, M. Sakurai, K. Suzuki, H. Adachi, H. Ino. Amorphous Fe Clusters Imbedded in fcc La for Melt-Quenched La-Fe Alloys. Journal de Physique IV Proceedings, 1997, 7 (C2), pp.C2-1015-C21016. 10.1051/jp4:19972122 . jpa-00255181

\section{HAL Id: jpa-00255181 https://hal.science/jpa-00255181}

Submitted on 1 Jan 1997

HAL is a multi-disciplinary open access archive for the deposit and dissemination of scientific research documents, whether they are published or not. The documents may come from teaching and research institutions in France or abroad, or from public or private research centers.
L'archive ouverte pluridisciplinaire HAL, est destinée au dépôt et à la diffusion de documents scientifiques de niveau recherche, publiés ou non, émanant des établissements d'enseignement et de recherche français ou étrangers, des laboratoires publics ou privés. 


\title{
Amorphous Fe Clusters Imbedded in fcc La for Melt-Quenched La-Fe Alloys
}

\author{
M. Matsuura, M. Sakurai*, K. Suzuki*, H. Adachi** and H. Ino** \\ Miyagi National College of Technology, Natori Miyagi 981-12, Japan \\ * Institute for Materials Research, Tohoku University, Sendai, 980, Japan \\ ** Faculty of Engineering, University of Tokyo, Bunkyo-ku Tokyo 113, Japan
}

\begin{abstract}
Fluorescence XAFS measurements of the Fe K-edge are done for melt-quenched La-rich La-Fe alloys. XAFS results of the as-quenched samples of $\mathrm{LagF}_{\mathrm{F}}$ and $\mathrm{Lasse}_{12}$ show characteristic features of disordered structure. The results for $\mathrm{LaszF}_{12}$ after annealed at $400^{\circ} \mathrm{C}$ for $30 \mathrm{~min}$. show that $\mathrm{Fe}$ are precipitated to $\alpha$-Fe in $\beta$-La. A strange phenomenon of finding the amorphous clusters in the crystalline phase can be attributed to the immiscible nature and large atomic size difference between $F e$ and $\mathrm{La}$.
\end{abstract}

\section{INTRODUCTION}

$\mathrm{La}$ and $\mathrm{Fe}$ are insoluble within each other and they do not form intermetallic compounds. The studies of structure and magnetic properties so far by Ino et al, see for example ref.[1] and [2] , proved that $\beta$-La is formed by rapidly quenching of $\underline{L a}-\mathrm{Fe}$ alloys $(1 \sim$ $12 \% \mathrm{Fe}$ ). No crystalline $\mathrm{Fe}$ is found by X-ray diffraction even at $12 \% \mathrm{Fe}$. Lattice parameters of $\beta$-La are constant despite of the increase in Fe concentration up to $12 \% \mathrm{Fe}$ suggesting that Fe atoms do not dissolved in $\beta$-La. Super paramagnetism of these La-Fe alloys at room temperature suggests the formation of Fe clusters in $\beta$-La. Disordered structure of Fe clusters is inspected from the distributed hyperfine field observed by Mössbauer measurements [3]. The main purpose of this work is to elucidate the local structure of Fe clusters by means of XAFS measurements.

\section{EXPERIMENTS}

Arc melted Las2 Fes and Lasse $F_{12}$ were melt-quenched by a single-roller melt-spinning technique. Sample thickness is about $30 \sim 50 \mu m$ and width about $1 \mathrm{~mm}$. Because of the very large absorption coefficient of $\mathrm{La}$ at the Fe $\mathrm{K}$-edge, the transmission method is not adequate for XAFS measurements and so the fluorescence method is aoopted. XAFS measurements of the Fe K-edge for the as-quenched $\mathrm{La}_{92} \mathrm{Fe}_{8}$ and $\mathrm{La}_{88} \mathrm{Fe}_{12}$, and the annealed Las8 $\mathrm{Fe}_{12}\left(400^{\circ} \mathrm{C}\right.$ for $\left.30 \mathrm{~min}\right)$ were done at $\mathrm{BL} 7 \mathrm{C}$ in Photon $\mathrm{Factory}$ of $\mathrm{KEK}$ using a Si(111) monochromator and a total reflection mirror. A Mn filter $(3 \mu \mathrm{m})$ was used as a Z-1 filter and an ion chamber as a detector combined with the Lytle collimating slit.

\section{XAFS ANALYSIS}

Fluorescence method is usually applied to a thin film or a dilute concentration. La-Fe alloy of $12 \%$ Fe seems to be out of dilute concentration range. But the ratio of the absorption jump $\Delta \mu\left(\mathrm{E}_{0}\right)$ at the $\mathrm{Fe} \mathrm{K}$-edge to total absorption $\mu_{\text {total }}\left(\mathrm{E}_{0}\right)$ is only $4 \%$ due to the large absorption coefficient of $\mathrm{La}\left(3067 \mathrm{~cm}^{-1}\right)$. Rough estimation of the part of the Fe EXAFS oscillation $\Delta \mu_{\mathrm{Fe}}(\mathrm{E})$ to the total absorption $\mu_{\text {total }}(\mathrm{E})$ is less than $0.14 \%$. Therefore a dilute approximation is applicable for the $\mathrm{Las}_{88} \mathrm{Fe}_{12}$ as well as $\mathrm{La}_{92} \mathrm{Fe} \mathrm{e}_{8}$ alloys.

After an usual background subtraction and normalization procedure, $\chi(k)$ was deduced. The resultant $\chi(k)$ and their Fourier transforms, $F(r)$, are shown in Figs. 1 and 2 together with that for pure $\alpha$-Fe as a reference. The k-range of the Fourier transform is from 2.5 to $13.5 \AA^{-1}$. Curve fitting was done for the present XAFS results using EXAFS2[4]. Cumulant expansion up to the fourth order was adopted as a fitting equation for the as-quenched samples because of the anharmonicity in the radial displacement for the disordered structure. As appropriate model compounds are difficult to be found for the present disordered structure, we use theoretical parameters calculated by ab initio method, FEFF[5]. Two model structures for the as quenched samples are examined; Fe in fce La and $\mathrm{Fe}$ in a hypothetical fce Fe; fcc is adopted as an alternative structure for dense random packing of hard spheres. The former can not fit the observed results while the latter fits well. Bcc Fe is adopted as a model compound for the annealed sample. The detailed curve fitting procedures were cited elsewhere[6]. The results of the curve fitting are listed in the Table 1. 


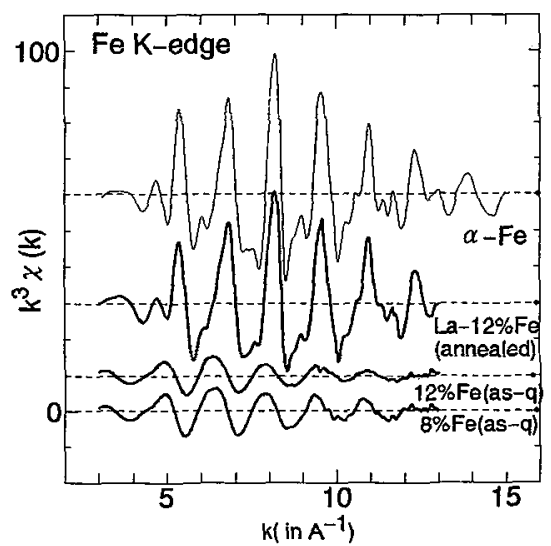

Fig. $1 k^{3} \chi(k)$ vs $k$ at the Fe K-edge for the as-quenched and annealed Lasz Fes and $\mathrm{L}_{28} \mathrm{Fe} e_{12}$, and $\alpha-\mathrm{Fe}$.

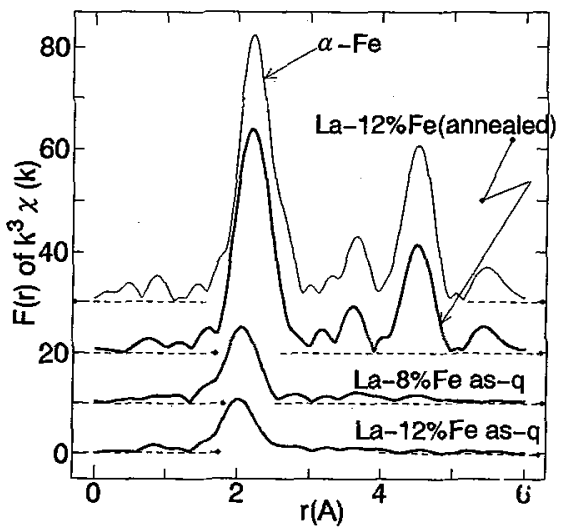

Fig.2 Fourier transforms of $k^{3} \chi(k)$ of the Fe K-edge for the as-quenched

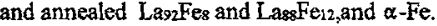

Table 1 Curve fitting results of the EXAFS spectra for La92Fes and Lass Fe $e_{12}$. ratomic distance, N.coordination number, $\mathrm{C}_{\mathrm{ij}}$ :Cumulants

\begin{tabular}{|c|c|c|c|c|c|c|c|c|}
\hline sample name & $\mathbf{r}(\AA)$ & $\mathrm{I}_{2}(\dot{\AA})$ & $\mathrm{N}_{\mathrm{l}}$ & $\mathrm{N}_{2}$ & $C_{21}(\sigma)\left(\AA^{2}\right)$ & $\mathrm{C}_{22}(\sigma)\left(\AA^{2}\right)$ & $\mathrm{C}_{3} \times 10^{3}\left(\AA^{3}\right)$ & $\mathrm{C}_{4} \times 10^{4}\left(\AA^{4}\right)$ \\
\hline $\mathrm{La}_{22} \mathrm{Fe}_{8}$ (as-q) & $2.492 \pm 0.02$ & & $4.07 \pm 2$ & & $0.081 \pm 0.05$ & & $0.282 \pm 0.005$ & $-0.078 \pm 0.005$ \\
\hline $\mathrm{L}_{288} \mathrm{Fe}_{12}$ (as-q) & $2.527 \pm 0.02$ & & $4.10 \pm 2$ & & $0.095 \pm 0.05$ & & $0.980 \pm 0.005$ & $-0.271 \pm 0.005$ \\
\hline $\mathrm{Lass}_{2 \mathrm{e}_{2} \text { (anneal) }}$ & $2.469 \pm 0.02$ & $2.810 \pm 0.02$ & $7.36 \pm 1$ & $6.71 \pm 1$ & $0.062 \pm 0.05$ & $0.088 \pm 0.05$ & & \\
\hline
\end{tabular}

\section{DISCUSSION}

The characteristics of the present XAFS results for the as-quenched one are that the local structures of $\mathrm{Fe}$ atoms in the La92 $\mathrm{Fe}_{8}$ and Lass $\mathrm{Fe}_{12}$ are very similar to each other and show a high degree of disorder; a small amplitude and a rapid decay of the $\chi(\mathrm{k})$ curve and low and broad peaks with no explicit long-distance structures in the $F(r)$ curve. On the other hand annealed Lass $\mathrm{Fe}_{12}$ exhibits a quite similar to those of pure $\alpha-\mathrm{Fe}$.

The disordered structure of the as-quenched $\mathrm{La}_{92} \mathrm{Fe}_{8}$ and $\mathrm{La} \mathrm{F}_{83} \mathrm{Fe}_{\mathrm{l}}$ seen in the present XAFS results is agreed with the distributed hyperfine field[3] and local structures of Fe clusters are inferred to be amorphous. It is not easy to determine precise size and concentration of the cluster. However it may be said that the nearest neighbor distance determined by curve fitting is close to iron(bcc and $f(c)$ and no definite structure of $\beta$-La are detected within about $6 \AA$ as seen in Fig.2. Therefore the size of the cluster is at least above $12 \AA$ in diameter. Although the reasons of the formation of such Fe clusters in crystalline $\beta$-La can not be clearly understood now the following can be inferred: in a rapid cooling process the immiscible nature of $\mathrm{Fe}$ in $\mathrm{La}$ inclines to exclude Fe from precipitated $\beta$-La and the remained liquid is enriched with Fe. This Fe rich melt can be solidified to a phase of an amorphous state or one with a high disordered structure because of the large atomic size difference, $r(\mathrm{Fe}) / \mathrm{r}(\mathrm{La})=0.69$.

\section{Acknowledgements}

The present work has been carried out under approval of the Photon Factory Program Advisory Committee(acceptance No.94G007). One of the authors, M.Matsuura, owes this work to the financial support by a grand-in-aid for scientific research, project No.07555189 from the Ministry of Education, Science, Culture and Sports, Japan.

\section{References}

[1] S.Kondo,E.Kita,K.Higasi,A.Saruyama,H.Ino,and K.Siratori,J.Phys.Condens Matter.6(1994)9393-9404.

[2] K.Siratori,E.Kita,S.Kondo, and H.Ino,J.Phys.Condens Matter.6(1994)9405-9414.

[3] K.Kawano,H.Ino and S.Nishikawa,Script.Metal,12(1978)333-335

[4] N.Kosugi,H.Kuroda,PROGRAM EXAFS2/N3,Research Cent. for Spectrochemistry,Faculty of Science,Univ.Tokyo,Tokyo, 1987.

[5] J.J.Rehr,J.Mustre de Leon,S.I.Zabinsky, and R.C.Albers,J.Am.Chem.Soc.113(1991)5135-5139.

[6] M.Matsuura,M.Sakurai,S-H.Kim,K.Suzuki and T.Tomida,J.Phys:Condens.Matter.7(1995)7087-7097. 